\title{
Relational citizenship as social networks: Immigrant youth's maps of their friendships
}

\author{
Yvonne Hébert, J enniferWen-shya Lee and Shirley Xiaohong Sun \\ Faculty of Education, University of Calgary
}

\section{Chiara Berti}

Facoltà di Lingue e Letterature Straniere, Università di Genova

\begin{abstract}
Seeking to understand what it means for immigrant youth to make new connections in a host country, we explore their networks of social relations and situate these with respect to social capital and to citizenship as a relational and spatial concept. Focusing on graphic representations of friendships of nearly sixty immigrant adolescents, the analysis examines the possible influences of gender, ethnicity, time and context; the philosophical meanings of the horizontal or vertical spatial orientation of these drawings; as well as the youth's own understandings of friendship. The findings indicate that holding a vertical, hierarchical and competitive orientation to friendship may be advantageous, in that the youth's understanding of friendship as a mutually alternating resource allows for weak ties of acquaintances to facilitate social mobility, the transportation of information and integration. Thus, the development of close friends to access the knowledge, skills and perspectives available in such friendships, family and school, is necessary but not sufficient to assure integration and participation in society. The notion of relational citizenship is expanded to include the development of both close friends and acquaintances for the former fosters an understanding of reciprocal trust while the latter allow for investment in action for the common good.
\end{abstract}

Key words: Immigrant youth, relational and spatial citizenship, orientations to friendship, representations, social networks, reciprocity

RESUMEN

Con el objetivo de comprender lo que significa para los jóvenes inmigrantes establecer nuevas relaciones en un nuevo país, exploramos sus redes de relaciones sociales, y las situamos en el marco de la ciudadanía, entendida como un concepto relacional y espacial. Utilizando representaciones gráficas sobre sus amistades producidas por aproximadamente 60 inmigrantes adolescentes, anal izamos posibles influencias de variables como genero, etnicidad, tiempo y contexto. Tambén exploramos el significado filosófico de la orientación espacial de los dibujos (verticual u horizontal), así como las propias definiciones de amistad elaboradas por los propios jóvenes. Los resultados sugieren que una orientación a la amistad vertical, jerárquica y competitiva puede ser ventajosa, en el sentido de que una comprensión de la amistad como un recurso de alternativas mutuas permite lazos débiles con conocidos para facilitar la movilidad social, el flujo de infor- 
mación, y la integración. Así, el desarrollo de amistades cercanas es una condición suficiente para acceder al conocimiento, las habilidades y las perspectivas disponibles en dichas amistades, pero no suficiente para asegurar la integración y la participación en la sociedad. Al expandir la noción de ciudadanía relacional, incluimos tanto a la formación de amigos y de conocidos; los primeros promueven la comprensión de la confianza recíproca, y los segundos permiten la inversión en acciones para el bien común.

Descriptores: J uventud inmigrante, ciudadanía relacional y espacial, orientaciones a la amistad, representaciones, redes, reciprocidad

\section{RÉSUMÉ}

Afin de comprendre le sens que font les jeunes immigrés de leur besoin de forger de nouvelles connections au pays d'accueil, nous explorons leurs réseaux de relations sociales et nous les situons par rapport au capital social et à la citoyenneté en tant que concept relationnel et spatial. M isant sur leurs représentations graphiques des amitiés de presque soixante jeunes immigrés, l'analyse examine les influences possibles du sexe, del'ethnicité, du temps et du contexte; le sens philosophique de l'orientation spatiale des dessins, soit horizontale ou verticale, ainsi que la compréhension de l'amitié qu'offrent les jeunes eux-mêmes. Les rendements indiquent qu'une orientation verticale, compétitive et hiérarchique vers l'amitié pourrait être avantageuse. Cette compréhension de l'amitié en tant que ressource en alternance mutuelle permet aux liens faibles des connaissances de faciliter la mobilité sociale, le transport de l'information, et l'intégration. Ainsi, la formation de proches amis afin d'avoir accès au savoir, aux skills et aux perspectives disponibles dans l'amitié, la famille et à l'école, est nécessaire mais non suffisante pour assurer l'intégration et la participation dans la société. La notion de la citoyenneté relationnelle doit donc inclure la formation de proches amis et de connaissances afin que les premiers puissent permettre la compréhension de la confiance réciproque de l'autre et les derniers puissent augmenter l'investissement dans l'action pour le bien commun.

Mots-cléfs: J eneusse immigrante, citoyenneté, relationnelle et spatiale, orientation, à l'amitié, représentation mentales, réseaux sociale, réciprocité

\section{Making Friends}

$\mathrm{T}$ HE PROCESS OF BECOMING CANADIAN crucially involves making new connections in the host country, without necessarily or completely losing touch with the connections in the country of origin. For immigrants, this means accessing and building connections to individuals who might help them to fit in better in the new world and thus achieve their goals as new $C$ anadians. This process of becoming is located within an understanding of citizenship as a relational and spatial concept, critically involving social networks. W hat then are the characteristics of social networks for immigrant youth? M ore specifically, how do adolescent immigrants construct and represent dutiful obligations and reciprocal transactions? $\mathrm{H}$ ow do they develop a sense of trust as well as a sense of bounded solidarity among friends and family members? These sociological ways of questioning social relationships, their development and maintenance, providea working framework for this paper.

In this light, we examine social representations of friendships drawn by nearly sixty immigrant adolescents so as to be able to determine what might betheir development and maintenance of social networks as forms of symbolic and relational power deemed socially and politically significant. In probing their understanding of friendship, the analysis focuses on their friendship networks and the possible influences of gender, 
ethnicity, time and context. Situated within a threeyear study of identity formation of over sixty immigrant youth participants, ${ }^{1}$ our analysis examines the potentiality and reality of adolescent immigrants' maps of their friendships, in order to understand how social relations are created, contested, increased and reconstructed, by these youth in the new $\mathrm{C}$ anadian context. N otions of temporality, spatiality, associativity and reciprocity, embedded in the graphic representations of self, symbols and others, and located in real, imaginary and physical areas of schools and elsewhere (H ébert, 2002), are of particular relevance to the analysis.

Theyouth's drawings are quantified and qual ified as individualized social networks in a context-sensitive analysis which looks at the level of trust in co-operative, reciprocal relations between family and friends, all embedded in personal and communal relations. The friendship networks reveal two basic orientations to friendship that appear to be sensitive to gender, ethnicity and time in country. 0 ur interpretation yields insights on the process of acquisition of the immigrant youth's social conditions in terms of social relationships as forms of power providing access to social goals and social control, all set in complex local-global worlds.

0 ur analysis contributes to the understanding of social network theory and of social capital, by extending the concept to adolescent immigrants, by operationalizing the notion with the youth's graphic and indicators, and by utilizing both qualitative and quantitative methods of analysis. M oreover, dwelling on notions of strong and weak ties, the former is reconsidered so as to dwell on emotional closeness rather than on the proximity of friendships. While strong ties provide support, weak ties are also seen as holding critical importance for the youth in question. In doing so, our analysis sheds new light on the significance of social networks for the development of citizenship-as-relation.

\section{Relational citizenship and the nature of friendship}

Citizenship is a relational concept. M ore than a legal notion, relational citizenship is based on a concept of the social or relational self and acknowledges that particularities of relationships play a part in constituting the meaning of individuals' lives and identities (K nop, 2001). C ritically involving the development of deep, personal friendships that are a clue as to what citizenship demands, Kingwell suggests that:

The relationship between citizens is friendly in the sense of feeling obligation and commitment to others - obligation and commitment that go beyond the abstract legalism of rights, using the faculty of imagination instead to make a connection between people, united by, if nothing else, their human vulnerability. This kind of connection, which grounds the larger goals of inclusiveness and justice, is a significant achievement. It is certainly a great deal more than we now have, when we often simply refuse to see in another person the same aspiration to belong, to be at home, that we know we feel in ourselves... By a delicate mutual reinforcement, the healthy political realm is al so the place where deeper friendships may find a ready soil. (2000, p. 175)

Analyzing three friendships among articulate philosophers (Socrates and C riton; M ontaigne et LaBoëtie; T heodor Adorno and Walter Benjamin), Kingwell argues that it is 
in deep friendship that close bonds are established, that perspectives, knowledge and skills are developed, and that these are foundational to participation in society as a new model of citizenship, further to rights-based citizenship or citizenship-as-belonging. Attractive ideas to add to the debate about the world we want, the enactment of this philosophical approach to participation is located in mutual relations, interactions and networks that emerge among human groups, as well as an integral level of trust, seen as the outcome of obligations and norms which adhere to the social structure, found within a particular group or community.

Philosophical understandings of the nature of friendship provide insight into posited meanings attributed to their significance. A person succeeds in individualizing himself, according to Ricoeur (1987 and 1990), by imputing to an 0 ther those aspects and value-objects of self which he desires to appropriate for himself and which he sees in himself. $\mathrm{H}$ aving friends is ordinarily considered to be the greatest of treasures even though friendships are subject to the fragility inherent in the good quality of human action and speech. The good and happy being has need of friends and friendship, which is an activity that can be described as a 'becoming'. Under the guise of need, a link is knotted between activity and life, and between happiness and pleasure, where friendship converges. Friendship implies a relationship situated between the 'me' and the 'other,' based upon a respect for oneself and mutual reciprocity. Respecting oneself allows a person to aim for the true life and for the other within just institutions and communities. The solicitude for self and other lies in a dialectic dimension between speakers and actors. A mutual relationship can create commonality, that is, a 'life together' in which sharing between a small number of persons concedes a place to the distribution of parts in a plurality of the scale of a community (Aristotle, in Ricoeur, 1990, p. 220).

The interplay that is friendship brings individuals to act together with greater power. Together, friends target the world as a common nature. Together, friends build communities that can act in turn upon the scene of contemporary life. The other becomes the source of help, of gathering, of affirmation, of the maintenance of one's identity. The other attests to one's actions and words, becomes one's conscience and in doing so, joins in the self 's identity. Friends are therefore affected; the other is no longer a passive being, but by his or her activity, is attached to and part of the self.

W ithin the N orth American culture of youth, two types of friendships may be distinguished: friendships that are cooperative and non-competitive; and hierarchical friendships. $\mathrm{N}$ on-hierarchical friendships are defined in terms of closeness, may be exclusive, and imply intimacy, equality, mutual commitment and loyalty (BrooksGunn \& M atthews, 1979; G oodwin, 1980; Lever, 1976). In hierarchical friendships, the relative status of friends is constantly fluctuating within the hierarchy. Since these hierarchies vary temporally, each person has the occasion of being dominated, must learn to accept it and to attempt to dominate others. N on-dominant persons are not excluded but are held to a position of inferiority. Posturing is the means by which participants constantly seek to adjust their position, to compete one against the other, in order to assume and maintain a good position ( $\mathrm{M}$ altz \& Borker, 1982).

The philosophical concept of mutuality of friendship varies according to the social 
organization of friendly and intimate relations. The role alternation between 'me' as dominating agent and the 'other' as dominated patient, fundamental to friendship according to Ricoeur (1990), may be learned as early as childhood; this then becomes the social norm for adherents of a hierarchical organization of social and work contacts in N orth America, including Canada (Pooler, 2000). H owever, this is not the only possibility for a concentric social organization, which may be situated with respect to other philosophical elements of friendship: affectivity and negotiation of interactivity towards solidarity, fidelity and consensus among themselves (H ébert, 1996; 1995). Such participants see themselves as equals in their actions and interactions. They seek not so much competition and domination as the creation and maintenance of egalitarian and friendly relations. These tend to correlate with gender in $\mathrm{N}$ orth America, with girls engaging in cooperative friendly relationships and boys in hierarchical and competitive ones, although not exclusively so with francophone minority youth ( $\mathrm{H}$ ébert, 1995; 1996). W hether immigrant youth would necessarily relate to their friends in the same gendered pattern remains an open question.

\section{Friendships as networks of social relations and as social capital}

For our purposes, a view of social relations as a dynamic, social, spatially, culturally, temporally and economically embedded group, network or constellation is of interest, especially if it has the young person at the core of the constellation and provides authentic opportunities for everyday learning (Raffo \& Reeves, 2000: p. 148). This perspective recognizes that systems of social relations both support and constrain individual actions and outcome as well as the extent to which individual change and development can occur (C otterell, 1996). Such systems are heavily dependent on the way individualized systems or constellations of people evolve for each individual young person, which is in turn conditioned by the material and symbolic resources available to these networks.

Four broad types of individualized systems of social relations may be distinguished: weak, strong, changing and fluid (Raffo \& Reeves, 2000). A weak individualized network of social relations is relatively small, provides little practical informal knowledge through the interactions of that network, is often not practice driven, and has little access to material and symbolic resources, resulting in a relatively passive and static articulation of individual change and development. A strong and yet fixed individualized system is driven from a concentration of opportunities for developing informal and practical knowledge and understanding. A changing individualized system changes over time, whereas a fluid indi vidualized system exhibits a significant degree of dynamism, flexibility and adaptability in response to changing circumstances and the changing biography of the young person. Social resources in this perspective are the result of a diversity of individuals, reflective of a wide range of relationships developed in a number of different contexts and providing a broad base of constantly updated reflexive knowledge. The changing dynamics within the lives of young people in the short, medium and long-term can and do create new social relations and evolving individualized networks. 
Interpersonal relational links, their sources and distinctive roles vary according to the amount of time invested, the emotional intensity, theintimacy of mutual confidences and the reciprocity of services (cf., Granovetter, 1973; H agan, 1998; Lemieux, 2000). Weak ties refer to acquaintances rather than close friends and to instrumental functions rather than emotional ones whereas strong ties presuppose geographical proximity, frequent interactions and greater functional specificity. Strong ties form among people who have opportunities to get to know each other well, which implies lesser diversity of information and of personal characteristics among close friends. This al so implies that acquaintances would be at a greater social and geographical distance, would know each other less well, and would be more likely to provide greater access to information and to different people. Weak social ties extend beyond intimate circles and establish inter-group connections upon which rest macro-social interactions, having a cohesive effect for self and society (Blau, 1974; Granovetter, 1983). Of critical importance to immigrants and refugees in the process of integration, weak ties enhance the individual's autonomy and access to a range of resources (C arrasco, Rose\& C harbonneau, 1999; H agan, 1998). H owever, the posited proximity and frequency of contact characteristic of strong links may be problematic in an electronic age when means of rapid communication make possible the maintenance of strong ties across great distances.

For immigrant youth, the development of interpersonal relational networks which may be emotionally close or not, would involve making new friends and acquaintances, maintaining old friends and family connections, then transforming them as necessary, so as to accumulate the individualized social goals and relations necessary to establish membership and to participate in the new club that is $\mathrm{C}$ anada. Thus social networks as goals and resources for immigrant youth would be located in the knowledge, perspectives, skills and goods of their families, friendships, schools, social groups and ethnocultural communities, popular culture, formal and informal organizations.

Essential to the normal development of children and adolescents ( $\mathrm{N}$ angle and Erdley, 2001), social networks of friends and family make possible the accumulation of social capital (Kilbride, 2000; Cotterell, 1996; Coleman, 1990). Social networks, shared norms and values, are critical component of social capital, which we understand as a macro-concept that has both collectivized and individualized dimensions. W hile there are many attempts at definition (cf., Bourdieu, 1986, 1977; Coleman, 1990, 1988; Putnam, 2001, 1995; and Portes, 1998), social capital can generally serve as resource, goal-orientation and social control (Wall, Ferrazzi and Schryer, 1998). W hat counts as social capital for children and youth, however, is poorly specified and has not been the subject of consensus (M orrow, 1999). N onetheless, the resurgence of interest in this concept as it concerns youth tends to focus upon individual ized social capital in the form of social networks, which permit their social and economic integration. This view is important for two reasons: it acknowledges that individuals hold within themselves the ability to facilitate the production of social capital (Paxton, 1999); and it recognizes that:

- The value of social capital depends heavily upon social setting or field;

- There is an important difference between possession and activation of social capital; 
- Social reproduction is not a smooth continual process, but is jagged and uneven, being constantly negotiated by social actors (Lareau \& H orvat, 1999); and

- It is in ordinary life settings, with family, friends and at school, that youth accumulate and utilize social capital (C oleman, 1988).

For the purposes of this paper, we see young people as learners engaged in a process of lifelong learning set in learning environments which include the family, community and school, set in overarching and interacting policy environments. M ore specifically, we focus on young people at the core of networks which may take the form of embedded groups or constellations of social relations, shared norms and values, and whose purpose is learning (R affo \& Reeves, 2000).

\section{Methodology}

Some sixty-seven youth of immigrant origins in eight junior and senior high schools in Calgary were invited to draw their networks of friends and to comment on them in a mini-interview in a tape-recorded focus group led by two research assistants. ${ }^{2}$ All participants were asked to put their names anywhere on the page and to freely draw the names of their close friends in close proximity to their own and of more distant friends farther away from their own name, all within a $11 \times 17$ inch sheet of white paper. Using symbols consisting of circles, squares, solid and dotted lines, the youth were instructed to code their friends' names according to gender, ethnicity, school and other information.

For the purposes of analysis, the sociograms were subsequently coded according to several elements: number of friends; number of emotionally close friends; number of friends of same or different ethnicity as respondents; number of friends at the same or different school; number of friends of the same or different gender; number of friends in a different country; and number of friends who are also family members. Three research assistants coded the data over different time periods between 2000-2002 and triangulated all coding to assure accuracy and consistency.

A content analysis examines the shapes of the sociograms and categorizes them into two basic orientations in space, which are then queried in terms of philosophical understandings of friendships. A quantitative approach explores the overall characteristics of the participants with respect to their friendship networks. D ue to the small sample size and the complexity of the participants' drawings for the graphic content analysis, descriptive analysis and correlation analysis were utilized. The correlation analysis allows us to examine the relationship between the two basic orientations of the sociograms, the participants' biographical information (e.g., time depth in Canada, gender, ethnicity), and the characteristics of the links in their friendship networks. The narrative data provided in the mini-interviews sheds light on the participants' understandings of their process of making friends and of integrating into Canadian society. 


\section{Profiles of Participants}

Fifty-eight participants of immigrant origins completed both the sociograms and the mini-interviews. The gender distribution is identical, with twenty-nine males and twenty-nine females. Approximately eighty-five percent of these participants were in grade nine (aged 14 to 15 years) at the time of the study and the other fifteen percent were in the tenth grade (aged 16 to 17 years). Participants originated in various world areas, with half of the participants from East and South East Asian countries, twentyone percent from South Asia, seventeen percent from the M iddle East, seven percent from Central and South American countries and five percent from other world areas (African, European, American). Twenty-eight percent of the participants had lived in $C$ anada for two years or less at the time of data collection. M orethan half had been in $C$ anada between three and nine years, and twenty-one percent have spent ten years or more in Canada.

\section{Two levels of analysis}

To respond to the original research questions, the analysis proceeds in two steps, making the questions more specific while doing so. First, we wonder about the nature of the immigrant youth's friendships. H ere we examine the graphic characteristics of the youth's renderings, categorize them and suggest an underlying philosophical meaning, then provide a statistical profile of the youth according to the basic orientations of their drawings. Second, we wonder how the participants' length of residence in Canada, their gender and their ethnicity might influence the adolescents' social networks. The analysis focuses upon the number of friends, those attending the same school as the participants' and those living outside Canada. Selected quotations from the accompanying mini-interviews provide additional insights into the youth's friendships.

\section{H ow do these youth understand their friendships? Why are there different orientations of the participants's social networks?}

In the first step of the content analysis, the youth's graphic representations of their friendships were categorized according to shape. In branching sociograms (Figure 1), twelve participants put their own names at the top of the page and their friends' names in a branching, tree like structure underneath the self, whether or not the friends' names were placed neatly in multiple parallel horizontal rows. In ten vertical linear sociograms (Figure 2), the friends' names were arranged along a simple vertical line, with the self situated at one end of the line. In four horizontal linear sociograms (Figure 3), the friends' names were arranged along a horizontal line, with their own name situated variably at one end or within the line towards the middle. In twenty-six circular shaped sociograms (Figure 4), the self's name is situated in the middle of the drawing and the friends' names located around the self in one or more concentric rings. In a fifth possibility, six participants represented their friendship networks with a combination (Figure 5) of two of the shapes described above. 


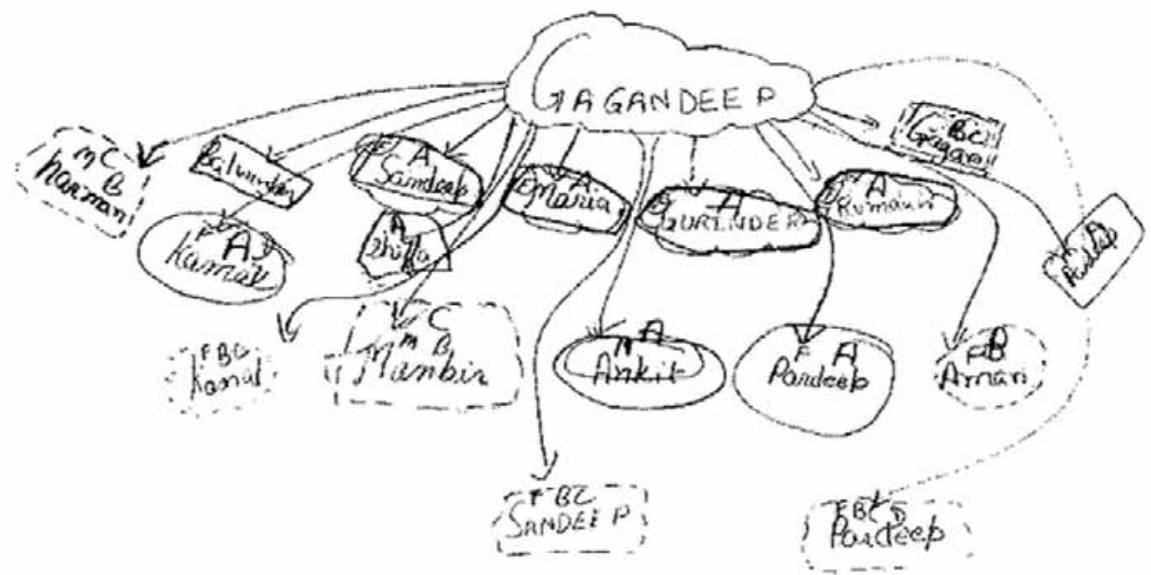

Figure 1. A branching social network.

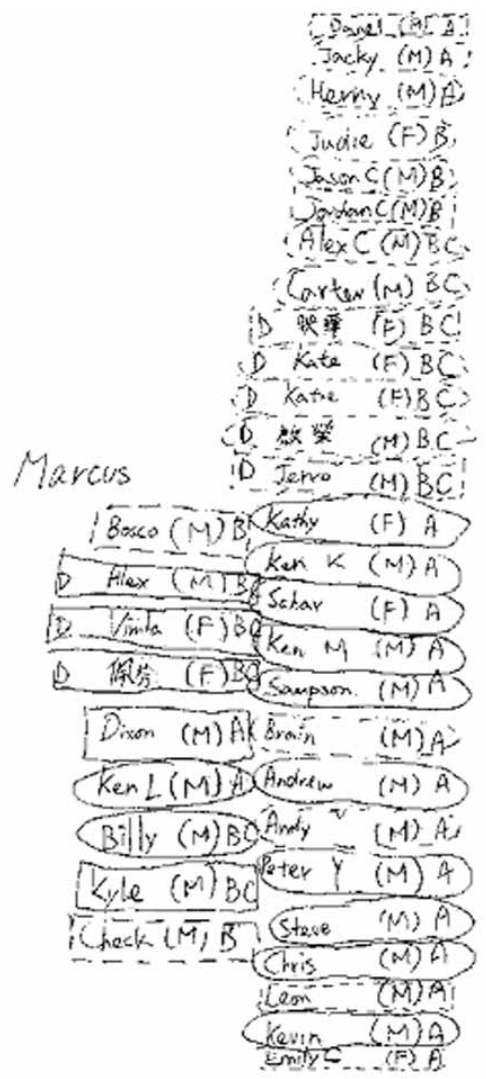

Figure 2. A vertical linear social network. 
92 Encounters/Encuentros/Renvontres

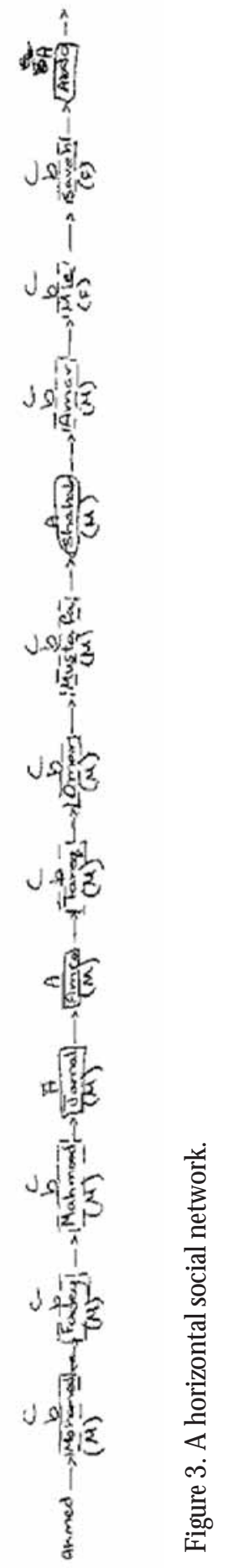



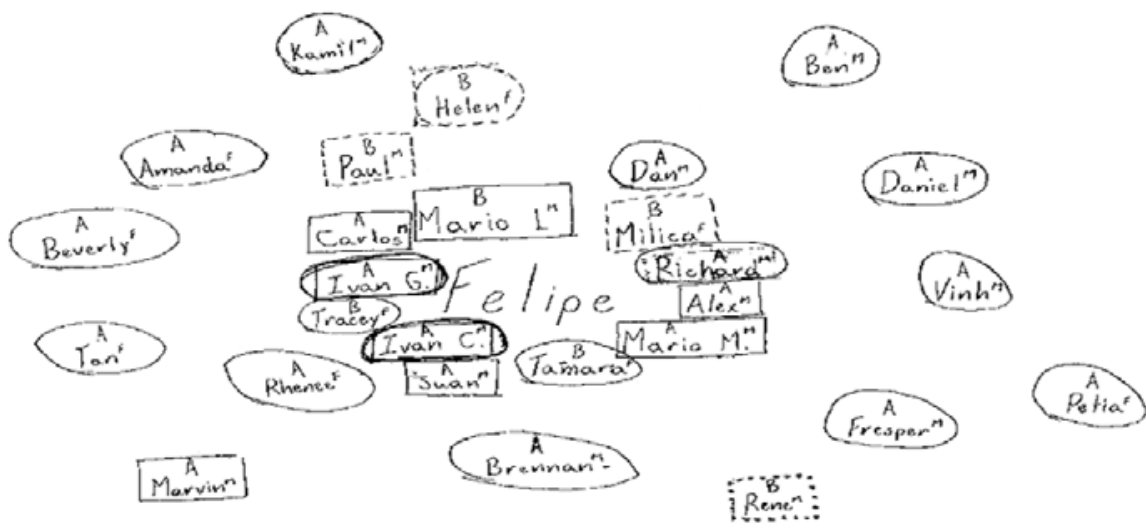

Figure 4. A circular social network.

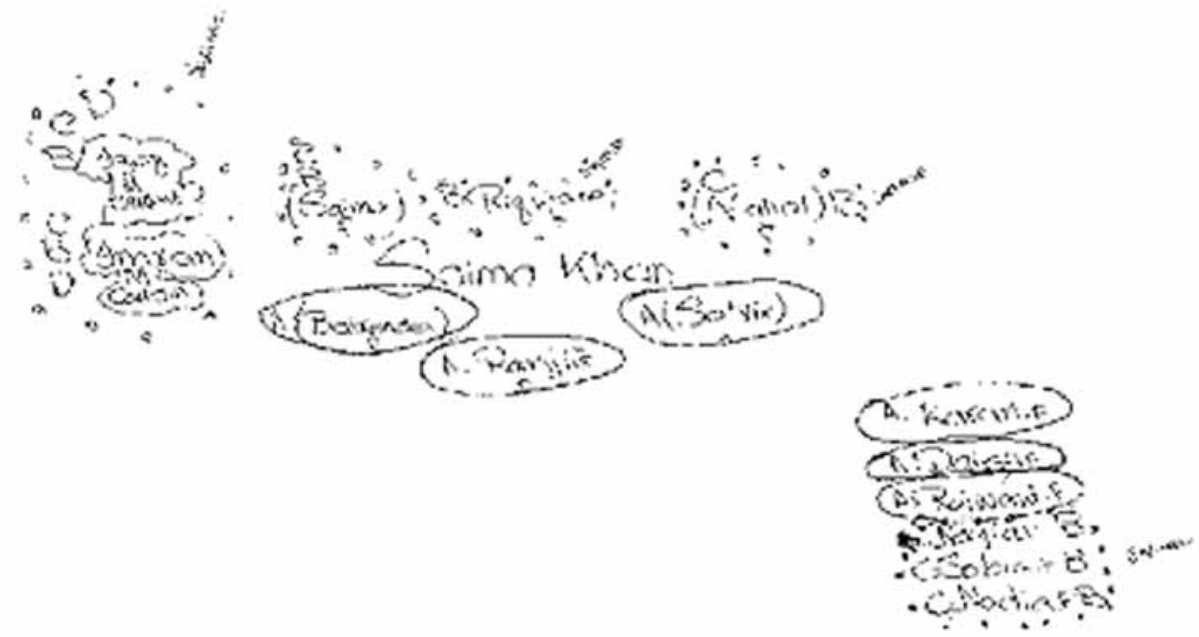

Figure 5. A combination drawing of a friendship network. 
In a second step of the content analysis, the sociograms were aggregated according to their orientation in space. A vertical orientation category includes twenty-three branching and vertical linear sociograms (39.7\%) whereas a horizontal orientation category includes thirty-one circular and horizontally oriented sociograms (53.4\%). Profiles of the youth with respect to the spatial orientation of their drawings in relationship to gender, time depth in country and areas of origin, are presented in Table 1. Thirty-one participants $(53.4 \%)$ represent their friendship networks by horizontal orientation, whereas twentythree participants (39.7\%) orient their friendship network vertically, and only four (6.9\%) combine two orientations in their sociograms.

Comparing the descriptive data of the two groups, the group characterized as having a horizontal orientation has higher percentages of males, new immigrant students and students originated from East and South East Asian countries. In contrast, the vertical orientation group has higher percentages of females, youth living in $\mathrm{C}$ anada between three and nine years, and youth from other world origins.

The drawings having a vertical orientation in two-dimensional space, map what are essentially hierarchical networks. These are understood philosophically as being competitive by nature and as being actualized in role-alternating dominating-dominated interrelationships. In comparison, those having a horizontal orientation are understood as being more egalitarian and imbued with other philosophical elements of friendship such as affection, solidarity, fidelity and negotiation of interactivity towards consensus.

Supportive of the philosophical understandings of friendships, the qualities sought after for good friendships were made explicit by the participating immigrant youth in their mini-interviews, especially by individuals who drew horizontal or combination images of their friendship networks: personality (benice, funny); respectful (of you and your ideas); trust (honesty, faithfulness, keeping secrets, responsible, no smoking/drugs so unlikely to lead astray); empathetic (understanding and caring); and similar interests. In response to the question "why is honesty important", one participant explained: "You don't want them to lie to you" (\#23, M, School C, East/South East Asian, H orizontal). Two other youth describe what they are looking for in a close friend: "They can keep secrets, are trustworthy, responsible, and they just cheer you up when you are down. They make you happy." (\#16, F, School B, E/SE Asian, H orizontal); and "I likea friend that is honest and who could understand my feelings. $\mathrm{H}$ e could understand what I want, and I could understand what he wants, that kind of person" (\#56, F, School G, South Asian/M iddle Eastern, Combo).

The common interests shared with friends include: intimacy and common leisure, study and sports activities, more specifically, talking; sharing every single thing, secrets; going for a nature walk, going to the downtown areas, shopping centers and leisure centers; studying together at the library, school work; and playing sports, playing videogames, pool. The following quotations illustrate the importance of common interests and activities to friendships: "O ur secrets, our thoughts and when we're having trouble we talk to them. And we go to places together" (\#56, F, School G; South Asian-M iddle Eastern origin; Combination O rientation); and "O $\mathrm{h}$ if I wasn't interested in sports then I wouldn't have any of these friends that I do have now" (\#62; $M$ ale; School H ; South Asian/M iddle Eastern; Vertical O rientation). 
What are the relationships between the participants' length of residence in Canada, gender, area of origin, and the spatial orientation of the immigrant youth's sociograms?

$M$ aking use of correlation analysis, we examine each of these in possible relationshipsin turn. Due to fewer cases in the combination group, further statistical analyses focus only on the vertical orientation and horizontal orientation groups. For similar reasons, the areas of origin retained for statistical purposes include only those of East/South East and South Asian/M iddle East ethnicities grouped together, as finer distinctions and more heterogeneity did not appear to be productive. Time depth in country was similarly grouped, for ease of analysis, into three time periods: 0-2 years, 3-9 years, and ten years or more.

Table 1: D istribution of Spatial O rientations of Friendship N etworks according to Gender, Time D epth in Country, and Areas of O rigin

\begin{tabular}{llll}
\hline Variables & $\begin{array}{l}\text { Vertical O rientation } \\
\mathbf{N}=\mathbf{2 3}\end{array}$ & $\begin{array}{l}\text { H orizontal O rientation } \\
\mathbf{N}=\mathbf{3 1}\end{array}$ & $\begin{array}{l}\text { Combination } \\
\mathbf{N}=\mathbf{4}\end{array}$ \\
\hline $\begin{array}{l}\text { Gender } \\
\text { M ale }\end{array}$ & $11(47.8 \%)$ & $17(54.8 \%)$ & $1(25.0 \%)$ \\
Female & $12(52.2 \%)$ & $14(45.2 \%)$ & $3(75.0 \%)$ \\
Total & $23(100 \%)$ & $31(100 \%)$ & $4(100 \%)$ \\
\hline Time depth & & & \\
0-2 years & $4(17.4 \%)$ & $11(35.5 \%)$ & $1(25.0 \%)$ \\
3-9 years & $15(65.2 \%)$ & $14(45.2 \%)$ & $1(25.0 \%)$ \\
10 years and over & $4(17.4 \%)$ & $6(19.4 \%)$ & $2(50.0 \%)$ \\
Total & $23(100 \%)$ & $31(100 \%)$ & $4(100 \%)$ \\
\hline Areas of origin & $10(43.5 \%)$ & $16(51.6 \%)$ & $3(75.0 \%)$ \\
East/South East Asia & $9(39.1 \%)$ & $12(38.7 \%)$ & $1(25.0 \%)$ \\
South Asia/M iddle East & $4(17.4 \%)$ & $3(9.7 \%)$ & $4(100 \%)$ \\
\hline Other & $23(100 \%)$ & $31(100 \%)$ & \\
\hline Total & &
\end{tabular}

In response to the specific question above, the correlational analysis shows that the participating youth who have lived in C anada for longer periods of time:

- $\mathrm{H}$ ave a higher number of friends over time (Table 2);

- $\mathrm{H}$ ave a higher percentage of their friends of an ethnic group other than their own and a lower percentage of their same ethnic group (Table 3);

- Report a lower percentage of friends living in a foreign country (Table 4);

- Report a higher percentage of friends attending their same school and a concomitant lower percentage of friends attending a school other than their own (Table5); and

- Tend to draw vertical social networks of friends if they are male and if they have lived in C anada for 3 to 9 years, than in other time periods (Table 6). 
O ne of the youth sheds some light on the wisdom of keeping friends over time: "I think that once you are in a friendship relationship, that's hard to forget and hard to begin all over again. Like my friends if I am going to meet them after three or five years later, they'd treat me the same as they treated me before. Like we know each other very, really well. We used to discuss everything together. We used to go to school by the same bus to go to school. We used to meet each other almost every hour" (\#51, M ale; School F; South Asian/M iddle Eastern; H orizontal O rientation).

Participants stressed the advantages of having the same cultural background in terms of greater understanding towards each other (\#29, M, School C, E/SE Asian, H orizontal), of greater affinity with a common religion or language ( $\# 25, M$, School C, SA/M E, H orizontal) or ease of communication with a shared language (\#17, M, School C, E/SE Asian, H orizontal; \#33, F, School C, O ther, H orizontal). In response to a question about feeling more comfortable with somebody who shares your culture, one young woman's words add meaning to the statistical pattern: "It would be nice because then you could talk with them, whatever you like to, in the language. Then you become good friends, and your parents don't mind you having a friend like that" (\#59, F, School G, South Asian/M iddle Eastern, H orizontal).

The reality of having a 'best friend' who is never around in any significant way is stressed: " $M$ y best friend is in Saudi Arabia... H e is from Syria, so we have different backgrounds, but we both speak the same, Arabic. Although we didn't get in touch with each other, he is the best friend of mine... because we share many things in common and because many things as I do here is the samething... he has donethe same. Even now he is in Saudi Arabia" (\#52, M , School F, SA/M E, horizontal orientation). This response, typical of youth with transnational connections, distinguishes between emotional closeness and proximity, key concepts intertwined in social network theory.

The moral dimension of friendship and group membership involves feelings of group obligation as well as feelings of attachment (Isajiw, 1999). These are elucidated by two particularly insightful youths:

M aybe because like they don't have to get along well with other people. M aybe their thoughts are different from others. So maybe they think that they are different. $0 r$, that they don't do the things that other people do. So somelike, those people are like very quiet and they don't really talk with any of the... I was like that when I came here but I'm changed, I am changed now. Because when you see a person from your country you are like, we are like... like relaxed and we feel like that. So, I think that people uh, that people who doesn't like, who is alone and doesn't talk with other people uh... I think his life would be, may be difficult from our point of view because he doesn't have any friends, he doesn't talk with anybody in the class, so too bad for him ( $\# 53$, Female, Vertical).

Explaining the importance of friends of the same background in the first few critical years, a young man comments: "I don't see an English person being really good friends with a person who can't speak English, like to be friends you sort of talk and stuff, and you can't talk to each other and not only friends... Language is really important. The only people that you can make friends with until you know a language are the people who can speak your own languages" (\#62, M, School H, South Asian/M iddle Eastern, Vertical). 
Table 2: Variation of the Average N umber of F riends according to Participants' Time D epth in Canada

\begin{tabular}{lccc}
\hline Time G roups & Group 1 (0-2 years) & Group 2 (3-9 years) & Group 3 (10 and over) \\
\hline $\begin{array}{l}\text { Friends } \\
\text { N umber of friends }\end{array}$ & 16.7 & 19.5 & 26.1 \\
\hline
\end{tabular}

Statistically significant relationship: $r=.339, p<.05$

Furthering the analysis of the relationships between participants' gender, ethnicity, time depth in C anada and spatial orientation of their sociograms, we find several points of comparison. In terms of gender differences, our findings indicate that:

- Girls tend to have more friends and a higher percentage of weak ties, in average per sociogram, than boys (Tables 7 and 8).

Table 3: M ean Variation of the Percentage of Friend's Ethnicity according to Participant's Time D epth in Canada

\begin{tabular}{lccc}
\hline Time G roups & Group 1 (0-2 years) & Group 2 (3-9 years) & Group 3 (10 and over) \\
\hline $\begin{array}{l}\text { Ethnicity } \\
\begin{array}{l}\text { Friends of same ethnicity } \\
\text { as respondent's }\end{array}\end{array}$ & .60 & .47 & .40 \\
\hline $\begin{array}{l}\text { Friends of other ethnicity } \\
\text { than respondent's }\end{array}$ & .32 & .43 & .59 \\
\hline M issing & .08 & .10 & .01 \\
\hline Total & 1.00 & 1.00 & 1.00 \\
\hline
\end{tabular}

Statistically significant relationship same ethnicity: $r=-.266, p<.05$; other ethnicity: $r=.352, p<.05$.

In terms of ethnicity, understood broadly here as world areas of origin for statistical purposes, the findings indicate that, in comparison with the East/South Asian youth in this study, the South Asian/M iddle Eastern participants:

- H ave a lower average number of friends per sociogram (Table 9);

- Show a lower percentage of friends of the opposite gender and a higher percentage of friends from their same gender in average per sociogram (Table 10);

- Report a lower percentage of friends attending their same school and a higher percentage of friends attending a school other than their own in average per sociogram (Table 11);

Table 4: M ean Variation of Percentage of Friend's C ountry of Residence according to Participantś Time D epth in Canada ${ }^{3}$

\begin{tabular}{lccc}
\hline Time G roups & Group 1 (0-2 years) & Group 2 (3-9 years) & Group 3 (10 and over) \\
\hline Country of residence & & & \\
Friends in foreign country & .47 & .12 & .09 \\
\hline Not reported & .53 & .88 & .91 \\
\hline Total & 1.00 & 1.00 & 1.00 \\
\hline
\end{tabular}

Statistically significant relationship: $r=-.543, p<.01$ 
- Report a higher percentage of friends living outside C anada in average per sociogram (Table 12); and

- Show a higher percentage of close friends and a lower percentage of weak ties in average per sociogram (Table 13).

Table 5: M ean Variation of Percentage of Friend's School of Attendance according to Participants' Time D epth in Canada

\begin{tabular}{lccc}
\hline Time G roups & Group 1 (0-2 years) & Group 2 (3-9 years) & G roup 3 (10 and over) \\
\hline $\begin{array}{l}\text { Friends school } \\
\begin{array}{l}\text { Friends in same school } \\
\text { as participant }\end{array}\end{array}$ & .38 & .64 & .64 \\
\hline $\begin{array}{l}\text { Friends in other school } \\
\text { than participant }\end{array}$ & .51 & .26 & .25 \\
\hline Not reported & .11 & .0 & .11 \\
\hline Total & 1.00 & 1.00 & 1.00 \\
\hline
\end{tabular}

Statistically significant relationship: same school: $r=.384, p<.05$; other school: $r=-.422, p<.05$

When they first come to $C$ anada, immigrant youth understandably tend to turn to friends within the same ethnic group, for sharing the same language and the same culture enhance their sense of security and identity in a new setting. Responding to a question about how they form a group of friends, a participant clarifies: " $M$ aybe when we have things in common. Like, we Pakistani, uh, for the immigrants because they have same language, they have same culture, so it is easy for them if they are in the group" (\#53, F, Vertical).

For the participating youth, schools cater to their needs of friendship and serve as important daily settings in which to build up their networks through trustworthy reciprocal social relations, providing opportunities to gain information, observe, ape and then confirm decisions and actions with significant others (Raffo \& Reeves, 2000). So, everyday informal and individual contacts are created through interaction, dialogue, action and reflection on action within situated school contexts. In response to a question on what common interests are shared, one participant explains: "We just like talk about, just talk about our studies and this stuff. Just talk like the two friends here in this school. I just talk about the school and my studies and just assignments and stuff, and things like that. I rarely talk with them about other things" (\#53, female, Vertical). School as a situated context "enables individuals to attempt to solve some of their everyday tasks and, at the same time, facilities their development of competence, self-esteem and identity" (Berger \& Luckman, 1966, cited in Raffo \& Reeves, 2000: p. 151).

In comparing the influence of the spatial orientation of the participants friendship networks, the findings indicate that:

- Youth who represented their friendship networks horizontally have a higher percentage of friends living outside C anada (Table 14); and

- Youth who represented their social networks horizontally have a lower percentage of weak ties (Table 15). 
Table 6: Variation of Spatial O rientation According to TimeD epth in Country within Gender Groups ${ }^{4}$

\begin{tabular}{|c|c|c|c|c|c|c|}
\hline \multirow[t]{2}{*}{ Time Groups } & \multicolumn{3}{|c|}{ M ale } & \multicolumn{3}{|c|}{ Female } \\
\hline & $0-2$ years & 3-9 years & 10 years+ & $0-2$ years & $3-9$ years & 10 years + \\
\hline \multicolumn{7}{|l|}{ Spatial 0 rientation } \\
\hline Vertical O rientation & $0 \%(0)$ & $56.3 \%(9)$ & $40.0 \%(2)$ & $50.0 \%(4)$ & $46.2 \%(6)$ & $40.0 \%(2)$ \\
\hline $\mathrm{H}$ orizontal $\mathrm{O}$ rientation & $100 \%(7)$ & $43.8 \%(7)$ & $60.0 \%(3)$ & $50.0 \%(4)$ & $53.8 \%(7)$ & $60.0 \%(3)$ \\
\hline Total & $100 \%(7)$ & $100 \%(16)$ & $100 \%(5)$ & $100 \%(8)$ & $100 \%(13)$ & $100 \%(5)$ \\
\hline
\end{tabular}

Statistically significant relationship, $c 2=6.46 ; p<05$

Table 7: Variation of theAverage N umber of Friends per Sociogram according to the Participants's Gender

\begin{tabular}{lcc}
\hline Respondents gender & M ales $n=28$ & Females $n=28$ \\
\hline $\begin{array}{l}\text { Average } \\
\text { Number of friends }\end{array}$ & 17.41 & 22.72 \\
\hline
\end{tabular}

Statistically significant relationship: $r=.286, p<.05$

Table 8: M ean Variation of the Percentage of Emotional Closeness according to Participants's $\mathrm{G}$ ender

\begin{tabular}{lcc}
\hline Respondents gender & M ales $\mathrm{n}=28$ & Females $\mathrm{n}=28$ \\
\hline Emotional Closeness & .51 & .38 \\
Strong & .40 & .56 \\
\hline Weak & .09 & .06 \\
\hline Missing & 1.00 & 1.00 \\
\hline Total &
\end{tabular}

Statistically significant relationship: $r=.315, p<.05$

Although the statistical analysis in itself cannot explain the adolescents' choice of a particular shape, it is the philosophical nature of friendship that illuminates the individual understanding of friendship and human relationships that add layers of meaning to their friendship networks. Further research would be necessary in order to develop a more accurate understanding of the meanings ascribed by the immigrant youth themsel ves to the spatial orientations of their social networks.

\section{Interpretation}

Theanalysis of our data provides support for friendship networks as significant and productive resources of immigrant youth. Friends from the same ethnic groups, gender group, schools, and family members considered as friends populate the young people's social networks and allow them to draw upon resources to cope with difficulties in daily life and with the process of integration to the host society. Given the productivity of social relations, the more friends the youth have, the better friend they become, and the more desirable they become as friends. As a result, friendship networks widen and grow. 
Table 9: $M$ ean Variation of the Percentage of Average $N$ umber of Friends per Sociogram according to Participant's Areas of O rigin

\begin{tabular}{lcc}
\hline Participants' Areas of O rigin & $\begin{array}{c}\text { East/South East Asian Youth } \\
\mathrm{n}=29\end{array}$ & $\begin{array}{c}\text { South Asian/M iddle Eastern Youth } \\
\mathrm{n}=22\end{array}$ \\
\hline $\begin{array}{l}\text { Average } \\
\text { N umber of friends }\end{array}$ & 23.6 & 15.9 \\
\hline
\end{tabular}

Statistically significant relationship: $r=-.39, p<.01$

Table 10: M ean Variation of Percentage of Friends' Gender according to Participant's Areas of $O$ rigin

\begin{tabular}{lcc}
\hline Participants Areas of O rigin & East/South East Asian Youth & South Asian/M iddle Eastern Youth \\
\hline $\begin{array}{l}\text { Friends G ender } \\
\text { Friends of the Same G ender as Participant's }\end{array}$ & .71 & .80 \\
\hline Friends of the O pposite Gender & .29 & .17 \\
\hline M issing & .00 & .03 \\
\hline Total & 1.00 & 1.00 \\
\hline
\end{tabular}

Statistically significant relationships: same gender: $r=.34, p<.05$; opposite gender: $r=-.40, p<.01$

Female adolescent immigrants in this study tend to serve as cultural brokers by having (1) a high number of friends; and (2) a high percentage of acquaintances, that is, emotionally weak ties. In general, these girls are more flexible to the changing circumstances, more open to the new things, more willing to accept the new ideas, find it easier to make friends and make bridging transitions. Since they have more friends and acquaintances than boys, girls appear to be fairly adept at circulating, keeping in touch, and negotiating. These communicative and interactive skills are involved in bridging and crossing cultural boundaries, regardless of whether these are ethnic, gender, or temporal borders.

Table 11: M ean Variation of Percentage of Friend's School of Attendance according to Participants' Areas of $O$ rigin

\begin{tabular}{lcc}
\hline Participants Areas of O rigin & $\begin{array}{c}\text { East/South East Asian Youth } \\
\mathrm{n}=29\end{array}$ & $\begin{array}{c}\text { South Asian/M iddle Eastern Youth } \\
\mathrm{n}=22\end{array}$ \\
\hline $\begin{array}{l}\text { School Attended by Friends } \\
\text { SameSchool }\end{array}$ & .63 & .44 \\
\hline Other school & .29 & .42 \\
\hline N ot reported & .08 & .14 \\
\hline Total & 1.00 & 1.00
\end{tabular}

Statistically significant relationships: same school: $r=-.36, p<.01$; other school: $r=.29, p<.05$ 
Several factors may influence the greater ease of adaptation among East/South Asian youth in our study. Peoples of East and South East Asia are more numerous and have been in $\mathrm{C}$ anada longer, thus its youth are probably more familiar to the general population. Cultural practices may also heighten the acceptability of the East/South Asians, especially in terms of politeness systems, gender roles, and usage of personal space in crowded situations, which is like living inside one self. For example, Chinese cultures are more accessible to the general public; again, for reasons of historical familiarity, there may be less discrimination and racism on a whole against the Chinese today, than towards other visible groups. The unstable situation in the M iddle East and the India/Pakistan sub-continent, may reflect poorly upon peoples who appear to come from this region of the world. And we must not discount the possibility of stereotypes negatively affecting Arab/South Asian groups. This provides some support for the greater number of strong ties among South Asian/M iddle Eastern youth, which would strengthen ties within the subgroup while also contributing to further social isolation. Since the East/SE youth have a higher number of friends; high percentage of friends of different sex; high percentage of friends within the same school; lower percentage of friends living outside Canada; and lower percentage of tight friendships; this finding suggests that the youth from East/South East group possess and are able to activate a richer store of social capital than the South Asians/M iddle East students.

Table 12: M ean Variation of Percentage of Friend' C ountry of Residence according to Participant's Areas of $O$ rigin

\begin{tabular}{lcc}
\hline Participants Areas of O rigin & $\begin{array}{c}\text { East/South East Asian Youth } \\
\mathrm{n}=29\end{array}$ & $\begin{array}{c}\text { South Asian/M iddle Eastern Youth } \\
\mathrm{n}=22\end{array}$ \\
\hline $\begin{array}{l}\text { Friends' Country of O rigin } \\
\text { Country O ther than Canada }\end{array}$ & .14 & .34 \\
\hline Not Reported & .86 & .66 \\
\hline Total & 1.00 & 1.00 \\
\hline
\end{tabular}

Statistically significant relationship for outside $C$ anada: $r=.37, p<.01$

Table 13: M ean Variation of Percentage of Emotional Closenessaccording to Participant's Ethnic dentity

\begin{tabular}{lcc}
\hline Participants Areas of O rigin & $\begin{array}{c}\text { East/South East Asian Youth } \\
\mathrm{n}=29\end{array}$ & $\begin{array}{c}\text { South Asian/M iddle Eastern Youth } \\
\mathrm{n}=22\end{array}$ \\
\hline $\begin{array}{l}\text { Emotional C loseness } \\
\text { Percentage of Strong Ties }\end{array}$ & .37 & .55 \\
\hline Percentage of Weak Ties & .56 & .40 \\
\hline M issing & .07 & .05 \\
\hline Total & 1.00 & 1.00 \\
\hline
\end{tabular}

Statistically significant relationships: close ties: $r=.36, p<.01$; weak ties: $r=-.31, p<.05$ 
Table 14: M ean Variation of Percentage of Friends Living outside Canada according to Spatial O rientation

\begin{tabular}{lcc}
\hline Spatial O rigin & $\begin{array}{c}\text { Vertical O rientation } \\
\mathrm{n}=23\end{array}$ & $\begin{array}{c}\text { H orizontal O rientation } \\
\mathrm{n}=31\end{array}$ \\
\hline $\begin{array}{l}\text { Friends } \\
\text { Outside Canada }\end{array}$ & .13 & .28 \\
\hline Not Reported & .87 & .72 \\
\hline Total & 1.00 & 1.00 \\
\hline
\end{tabular}

Significant relationship for outside $C$ anada: $r=.276, p<.05$

Table 15: M ean Variation of Percentage of Emotional C losenessaccording to Sociogramś Spatial Orientation

\begin{tabular}{lcc}
\hline Sociogram O rientation & $\begin{array}{c}\text { Vertical O rientation } \\
\mathrm{n}=23\end{array}$ & $\begin{array}{c}\text { H orizontal O rientation } \\
\mathrm{n}=31\end{array}$ \\
\hline $\begin{array}{l}\text { Emotional C loseness } \\
\text { Strong }\end{array}$ & .40 & .48 \\
\hline Weak & .56 & .39 \\
\hline M issing & .04 & .13 \\
\hline Total & 1.00 & 1.00 \\
\hline
\end{tabular}

Significant relationship for outside Canada: $r=.276, p<.05$

In other words, the participating youth's individualized system of social relations changes fluidly over time, exhibiting a significant degree of dynamism, flexibility and adaptability in response to changing circumstances and the changing biography of the young person. Time depth in $\mathrm{C}$ anada is a critical variable as it affects the number of friends and the nature of their ties and relationships. Participants living in $\mathrm{C}$ anada longer tend to have: (1) a high number of friends; (2) a high percentage of friends from different ethnic groups; (3) a high percentage of friends from the same school; and (4) a lower percentage of friends living in a country other than Canada. As the immigrant youth gradually integrate into the host country, they tend to loosen their ties to their friends in the country of origin and friends in the same ethnic group, and they make more friends here and extend their circles of friend outside the ethnic group. As the youth in this study become more and more familiar with the new society, they start to make friends outside their ethnic group and make fewer contacts with friends in their home countries. Thus the number of friends of the same ethnicity and living in a country other than $\mathrm{C}$ anada decreases and the number of friends of different ethnicity increases over time. In so doing, these youth are grounding themselves in $\mathrm{C}$ anadian culture, they are living $C$ anadian multiculturalism, and they are learning to master the symbolic and relational codes embedded in the host society. 
$\mathrm{H}$ aving the participants' draw their own map of their social networks is more insightful than having the analyst produce a graphic representation of the data, as is the usual case in analyses of social networks. Although these are messy data, as is most qual itative data, they bring out definitional and philosophical issues. First, the definition of basic terms to qualify ties as 'strong' and 'weak', has been seen here to hinge on emotional closeness rather than proximity, whereas the drawings' orientation in space are layered with philosophical meaning. It is not only the structural nature of the ties, as strong or weak, which is at the heart of friendship networks, but rather their emotional closeness. The participating youth maintain transnational connections, over great distances, subject to length of residence in the new country, which brings the youth to make more connections in their locality and gradually become less close to their friends in their countries of origin.

Secondly, the prevalence of the hierarchical orientation in the middle years of settlement, after the first two years of crisis, raises questions about the intensity and depth of the integration process. These synchronic data suggest that youth may even change their basic orientation to friends in order to fit into society. While this topic is in need of additional diachronic research with a larger number of youth, the possibility of a shift over time would coincide with the dominant social structural organization in mainstream N orth American society. This clearly would have implications for immigration policies and services for children and youth, as well as educational policy and practices regarding identity formation of immigrant youth.

\section{Conclusion}

$\mathrm{H}$ olding a vertical, hierarchical and competitive orientation to friendship may be advantageous in $\mathrm{C}$ anada whose work world and organizations are overwhelmingly organized in hierarchical structures (Pooler, 2000). W hile the two basic philosophical orientations to friendship tend to correlate with gender, this is not exclusively a function of gender, but rather of the youth's understanding of the nature of friendship and the function of weak ties for social mobility, the transportation of information, and integration (C arrasco et al, 1999; Granovetter, 1973; H agan, 1998). H owever, the notion of mutuality appears to differ according to the types of sociograms. The youth who drew horizontal networks interpret friendship as revolving around the notion of alternating roles in 'mutuality-as-alternation' whereas the horizontal types seem to understand their priorities as 'mutuality-as-consensus and mutuality-as-strategy.'

Theyouth in this study make use of social capital as a resource and as a goal. At the earliest stage of integration, social capital as a resource is particularly important. The participants draw upon their friendship from their own ethnic group to cope with the difficulties in new settings, for sharing the same language and culture comforts, and to ease anxiety and isolation. 0 verall, the participating youth actualize a goal of increased individual status, by using their social networks as adaptive strategies to integrate into their daily lives in Canada. O ver time, they make many friends from the same school and neighborhood to help them improve their social status, accumulating social capital 
as a goal and creating themselves strategically. After a while they start to make friends from other ethnic groups, and the number of friends of the same ethnicity decreases over time.

As our analysis makes clear, close friends are necessary but not sufficient to assure integration of immigrant youth and prepare participation in society. Thus the notion of relational citizenship is to be expanded to focus on the development of both close friends and acquaintances for it is the latter that allow for loose affiliations, the spread of information and investment in action for the common good. While youth develop social relations to access the knowledge, skills and perspectives available in friendships, family and school, it is youth with more weak ties that are more likely to participate in the transportation of information, beliefs and innovations; and to develop feelings of trust towards others and a greater sense of belonging.

These findings al so hold implications for immigration and educational policies and practices. The social integration of immigrant youth would be enhanced by the development of weak ties between different ethno-cultural and mainstream groups, rather than an exclusive focus on the establishment of strong, close friendships, especially in strongly bounded cliques within schools.

\section{Notes}

1. The research project, Identity Formation: Strategic Competence of Immigrant Youth, with D r. Yvonne H ébert as principal investigator and the other authors as research assistants, is funded by a three year standard grant from SSH RC, a one-year grant from the M ulticulturalism Programme of $\mathrm{C}$ anadian $\mathrm{H}$ eritage as well as travel grants over this period from the Prairie Centre of Excellence for Research on Immigration and Integration, part of the M etropolis research network.

2. The data were collected by Christine Racicot and Rani M urji in W inter-Spring 2000; and were coded and triangulated by C hristine Racicot, Chiara Berti and Jennifer Wen-shya Lee.

3. In Tables 4 and 5 , the missing data may be a function of the code provided to the participants to mark those friends who are not in Canada and the absence of a code for friends who are in C anada, or may have simply been missed by the youth, or may indicate an absence of friends in another country and/or at school.

4. This finding must be interpreted with caution, however, because of the small numbers of participating youth in $\mathrm{C}$ anada for over ten years. For each gender, only two individuals drew vertical networks and three drew horizontal ones. There is no significant relationship, however, between time depth in country and the spatial orientation of the sociograms for females. 0 ther time groups for both genders appear to have a similar number of immigrant youth representing their friendships either vertically or horizontally

\section{References}

Berger, P. and Luckman, T. (1966). The social construction of reality: A treatise in the sociology of knowledge Garden City, NY: D oubleday.

Blau, P. (1974). Parameters of social structure. American Soci ological Review, 39(5), 615-635.

Bourdieu, P. (1986). The forms of capital. In J. G. Richardson (Ed.), H andbook of theory and research for the sociology of education (pp. 241-258). W estport, CN : G reenwood Press, Inc. 
Bourdieu, P. (1977). Cultural reproduction and social reproduction. In J. Karabel and H. J. $\mathrm{H}$ alsey (Eds.), Power and ideology in education (pp. 487-511). N ew York: 0 xford U niversity Press.

Brooks-Gunn, J. and M atthews, W.S. (1979). Heand she: H ow children develop their sex-role identity. Englewood Cliffs, N .J.: Prentice-H all.

Carrasco, P., R ose, D. and C harbonneau, J. (1999). La constitution de liensfaibles: Une passerelle pour l'adaptation des immigrantes centro-américaines mères de jeunes enfants à M ontréal. Études ethniquesau Canada, 31(1), 73-91.

Coleman, J. S. (1997). Family, school, and social capital. In L. J. Saha, (Ed.), International encyclopedia of the sociology of education (pp. 623-625). O xford, U K: Pergamon.

Coleman, J. S. (1990). Foundations of social theory. Cambridge, M ass: H arvard University Press.

Coleman, J. S. (1988). Social capital in the creation of human capital. American Journal of Sociology, 94 (suppl): S95-S120.

Cotterell, J. (1996). Social networks and social influences in adolescence. London: Routledge.

Goodwin, M . (1980). Hesaid-she-said: Formal cultural procedures for the construction of a gossip dispute activity. American Ethnol ogist, 7(4), 674-695.

Granovetter, M . (1983). The strength of weak ties: A network theory revisited. Soci ol ogical Theory, 1, 201-233.

Granovetter, M . (1973). The strength of weak ties. American Journal of Sociology, 78(6), $1360-1380$.

H agan, J.M . (1998). Social networks, gender, and immigrant incorporation: Resources and constraints. American Sociological Review, 63(1), 55-67.

H ébert, Y. (2002). Identity, diversity, and education: A critical review of the literature. Canadian Ethnic Studies, 33(3), 155-185.

H ébert, Y. (1996). M es amis sont bilingues, comme M O I! In Benoît C azabon (Ed.), Pour un espace de rechercheau Canada français: D iscours, objets et méthodes (pp.141-158). 0 ttawa: Actexpress, Les Presses de l'U niversité d'O ttawa.

H ébert, Y. (1995). C hoice of friends and of identity among minority youth: A case study of Francophone adolescents. In Keith M cLeod (Ed.), M ulticultural education: Thestate of the art. Volume 2: Studies of Canadian heritage (pp.76-87). N epean: C anadian Association of Second Language Teachers.

Isajiw, W. (1999). U nderstanding diversity: Ethnicity and race in the Canadian context. Toronto: Thompson Educational Publishers.

Kilbride, K. M . (2000). A review of the literature on the human, social and cultural capital of immigrant children and their families with implications for teacher education. http://ceris.metropolis.net/V irtual\%20Library/education/kilbride2.html

Kingwell, M . (2000). Theworld we want: Virtue, vice and the good citizen. Toronto: Viking, Penguin Group.

Lareau, A. and H orvat, E. M . (1999). M oments of social inclusion and exclusion: Race, class, and cultural capital in family-school relationships. Sociology of Education, 72(1), 37-53.

Lemieux, V. (2000). À quoi servent les réseaux sociaux? Sainte-Foy: Les Presses de I'U niversité Laval.

Lever, J. (1976). Sex differences in the games children play. Social Problems, 23(4), 478-483.

M altz, D .N . and Borker, R. (1982). A cultural approach to male-female miscommunication. In John J. Gumperz (Ed.), Language and social identity (pp. 195-216). C ambridge: Cambridge University Press.

M orrow, V. (1999). Conceptualising social capital in relation to the well-being of children and young people: a critical review. Sociological Review, 47(4), 744-765.

N angle, D. W. and Erdley, C. A. (Eds.) (2001). The role of friendship in psychological adjustment. N 0. 91, of the series N ew directionsfor child and adolescent development. San Francisco: Jossey-Bass. 
Pooler, J. A. (2000). H ierarchical organization in society: A Canadian perspective H ampshire, UK/Burlington, VT: Ashgate Publishing C 0 .

Portes, A. (1998). Social capital: Its origins and applications in modern sociology. Annual Review of Sociology, 24(1), 1-14.

Putnam, R. D. (2001). Social capital: M easurement and consequences. Isuma, 2(1), 41-51.

Putnam, R. D. (1995). Bowling alone: America's declining social capital. Journal of D emocracy, $6(1), 65-78$.

Raffo, C. and Reeves, M. (2000). Youth transitions and social exclusion: D evelopments in social capital theory. Journal of Youth Studies, 3(2), 147-166.

Ricoeur, P. (1990). Soi-même comme un autre. Paris: Éditions du Seuil.

Ricoeur, P. (1987). Individu et identité personnelle. In P. Veyne et al., Sur l'individu, Contributions au colloque de Royaumont (pp.54-72). Paris: Éditions du Seuil.

Wall, E., Ferrazzi, G ., and Schryer, F. (1998). Getting the goods on social capital. Rural Sociology, 63(2), 300-322. 